\title{
(6) OPEN ACCESS \\ Acute Recanalization of Thrombo-Embolic Ischemic Stroke with pREset (ARTESp): the impact of occlusion time on clinical outcome of directly admitted and transferred patients
}

\author{
Sascha Prothmann, ${ }^{1}$ Benedikt J Schwaiger, ${ }_{1}^{1}$ Alexandra S Gersing, ${ }^{1}$ Wolfgang Reith, ${ }^{2}$ \\ Thomas Niederstadt, ${ }^{3}$ Alexandra Felber, ${ }^{4}$ Wiebke Kurre ${ }^{5}$
}

- Additional material is

published online only. To view please visit the journal online (http://dx.doi.org/10.1136/ neurintsurg-2016-012556).

${ }^{1}$ Abteilung für Diagnostische und Interventionelle

Neuroradiologie, Klinikum rechts der Isar, Technische Universität München, München, Germany ${ }^{2}$ Klinik für Diagnostische und Interventionelle Neuroradiologie, Universitätsklinikum des Saarlandes, Homburg/Saar, Germany

${ }^{3}$ Institut für Klinische Radiologie, Universitätsklinikum Münster, Münster, Germany

${ }^{4}$ Institut für Diagnostische und Interventionelle Radiologie und Neuroradiologie, Ev. Stift St. Martin, Gemeinschaftsklinikum Mittelrhein, Koblenz, Germany ${ }^{5}$ Neuroradiologische Klinik, Klinikum Stuttgart, Stuttgart, Germany

Correspondence to Dr Sascha Prothmann, Abteilung für Diagnostische und Interventionelle Neuroradiologie, Klinikum rechts der Isar, Technische Universität München, Ismaninger Strasse 22, München 81675, Germany; prothmann@tum.de

Received 4 June 2016 Revised 14 July 2016 Accepted 19 July 2016 Published Online First 15 August 2016

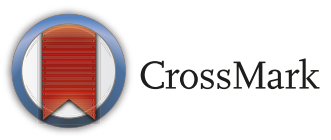

To cite: Prothmann $S$, Schwaiger BJ, Gersing AS, et al. J Neurolntervent Surg 2017:9:817-822.

\section{ABSTRACT}

Objectives Acute Recanalization of Thrombo-Embolic Ischemic Stroke with pREset (ARTESp) is a prospective multicenter study assessing the efficacy and safety of the pREset stent retriever for the treatment of intracranial vessel occlusion. Determination of the effect of transfer status on clinical outcome was a secondary objective. Methods Efficacy was measured by recanalization success (Thrombolysis in Cerebral Infarction score $\geq 2 b$ ) and favorable clinical outcome at 90 days (modified Rankin Scale 0-2). Intracranial hemorrhage (ICH) and death at 90 days were safety measures. The outcome of directly admitted (DAP) and transferred (TP) patients was investigated using multivariable regression models. Results Four study centers included 100 patients (mean age 68.3 years, median National Institutes of Health Stroke Scale score 15). Recanalization success was achieved in $84.4 \%$ after a mean of 1.7 passes. ICH was detected in $14.0 \%$, with $2.0 \%$ being symptomatic. At 90 days, $62.5 \%$ of the patients had a favorable outcome and $7.3 \%$ died. TP had longer occlusion times (289 vs 180 minutes, $\mathrm{p}<0.001$ ) and a lower rate of favorable outcome ( $58.0 \%$ vs $78.4 \%, p=0.046)$ than DAP. Multivariable regression revealed occlusion time as the critical determinant $(\mathrm{OR}=0.963,95 \% \mathrm{Cl} 0.931$ to 0.997, $p=0.032$ ), whereas transfer status itself showed no significant association $(\mathrm{OR}=0.565, \mathrm{Cl} 0.133$ to 2.393, $p=0.438$ ).

Conclusions pREset proved to be safe and effective for the treatment of acute intracranial vessel occlusion. Increased occlusion time impaired clinical outcome in TP. Trial registration number NCT02437409; Results.

\section{INTRODUCTION}

The efficacy of mechanical thrombectomy (MT) in patients with acute ischemic stroke caused by embolic proximal vessel occlusion was recently proved by five randomized controlled trials (RCTs). ${ }^{1-5}$ The positive results of these trials were mainly driven by the use of very effective stentlike retrievers, which were first introduced in $2008,{ }^{6}$ and barely used in previous trials..$^{7-9}$ Currently, several devices belonging to the family of 'stent retrievers' are available but each has undergone very different stages of scientific evaluation. The performance of the Trevo retriever (Stryker, Kalamazoo, Michigan, USA) and the Solitaire FR revascularization device (Covidien/
Medtronic, Dublin, Ireland) has been evaluated in multicenter studies. ${ }^{10}{ }^{11}$ For the pREset thrombectomy device (phenox, Bochum, Germany), data of retrospective single-center studies demonstrated a safety and efficacy profile comparable to that of other stent retrievers. ${ }^{12}{ }^{13}$ Prospective data from a multicenter study with defined inclusion and exclusion criteria and core-laboratory evaluation are lacking. Thus the primary purpose of the Acute Recanalization of Thrombo-Embolic Ischemic Stroke with pREset (ARTESp) study was to assess the safety and outcome after MT with the pREset device under controlled study conditions.

Similar to treatment with IV thrombolysis (IVT), it is assumed that the odds for favorable outcome after MT substantially depend on the occlusion time of cerebral arteries. ${ }^{14-19}$ Since MT is less widely available than IVT, a relevant proportion of patients needs a secondary transfer after the diagnosis of large vessel occlusion. Thus, MT is delayed in transferred patients compared with patients directly admitted to an endovascular stroke center. This hypothetically results in less favorable clinical outcome. Since in all study centers a relevant proportion of patients with stroke are secondary referrals, data of ARTESp were used to investigate the impact of secondary transfer on clinical outcome.

\section{MATERIALS AND METHODS Study design}

ARTESp is a prospective, multicenter, single-arm, post-market clinical follow-up study to evaluate the safety and clinical outcome of MT with the pREset thrombectomy device in eligible patients. The study was approved by the local ethics committees of all participating centers and registered at ClinicalTrials. gov (NCT02437409).

\section{Study subjects}

Between February 2013 and February 2015, consecutive patients undergoing MT in four centers were screened for ARTESp inclusion and exclusion criteria. Key inclusion criteria were proven occlusion of the internal carotid artery (ICA), M1 or M2 segments of the middle cerebral artery (MCA), vertebral artery or basilar artery, a National Institutes of Health Stroke Scale (NIHSS) score of 8-30 and groin puncture within 6 hours after symptom onset. Patients $<18$ and $>85$ years of age and/or 
with extended infarct demarcation according to the judgment of the local investigator were excluded. Patients provided informed written consent before study inclusion. If patients were unable to provide informed consent, their legal guardian acted on behalf. A comprehensive list of inclusion and exclusion criteria is provided as online supplementary material.

\section{Participating centers}

All study centers introduced MT between 2007 and 2009 and perform at least 60 procedures annually. Participating interventionalists were trained in device handling and independently completed at least 25 procedures with pREset before study entry.

\section{The pREset device}

pREset is a laser-cut nitinol stent retriever with a closed-cell design (figure 1). A helical slit along the device body allows for optimal adaptation to the vessel diameter, while preserving the closed-cell configuration. The proximal cells are connected with a ring to maintain a stable opening and to reduce tapering in vessel curves. There are one proximal and two distal radiopaque markers. pREset 4-20 and 6-30 were evaluated in ARTESp, with the first number representing the maximum diameter in millimeters and the latter the usable length between the distal marker and the proximal ring. pREset was approved in Europe in August 2011.

\section{Endovascular treatment}

Procedures were performed either under local anesthesia, conscious sedation, or general anesthesia, according to the respective institutional guideline. The interventionalist chose the access site, access material, microcatheter, and micro-guidewire, taking device compatibility into account. The use of a balloon-guide catheter or intermediate catheter was not mandatory. The procedure was performed according to the official instructions for use of pREset.

\section{Imaging evaluation and technical outcome}

All imaging data were subject to independent and blinded corelaboratory evaluation. Pretreatment imaging was evaluated for compliance with inclusion and exclusion criteria. Collateral flow was assessed on angiographic images according to the Higashida score. $^{20}$ Recanalization results were rated after the final pass with pREset and in the final angiographic series using the original Thrombolysis in Cerebral Infarction score (o-TICI). ${ }^{20}$ All possible procedure- and device-related events were recorded.

Post-treatment imaging was performed at 24-48 hours and evaluated for hemorrhagic events, including subarachnoid hemorrhage and parenchymal hematoma (PH) types II and I, according to the European Cooperative Acute Stroke Study definition. $^{21}$

\section{Clinical assessment}

The modified Rankin Scale (mRS) was assessed before the intervention, at discharge, and at 90 days either during a follow-up visit or by telephone interview. ${ }^{22}$ The pre-stroke mRS was estimated according to the information provided by the patient,

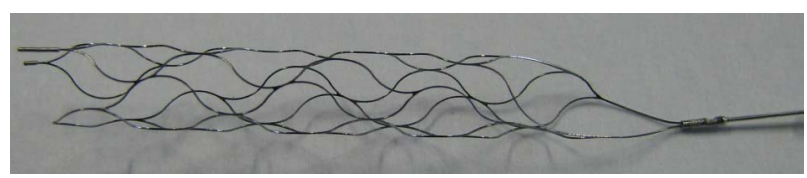

Figure 1 Study device pREset 4-20. relatives, or legal guardian. The NIHSS was assessed before treatment, at 24-72 hours after treatment, and after 7 days or discharge, whichever came first.

\section{Study endpoints}

The primary clinical endpoint was the degree of stroke-related dependency at 90 days measured using the mRS. For analysis the score was categorized defining mRS $0-2$ as favorable, mRS $0-1$ as very good, and mRS 0 as excellent outcome.

Secondary endpoints were recanalization success achieved with the study device, defined as o-TICI $\geq 2 \mathrm{~b}$ after a maximum of five passes and the average number of passes required for successful recanalization.

Imaging hemorrhage and death rate at 90 days served as safety measures. Symptomatic hemorrhage was defined as any hemorrhage leading to deterioration of the NIHSS score of $>3$ points or death within 24 hours.

The secondary objective was assessment of process time parameters, which were compared between directly admitted (DAP) and transferred patients (TP).

\section{Statistical analysis}

Baseline demographic and medical history data, process time parameters, technical and clinical outcome, and adverse events were assessed for the complete study population using descriptive statistics.

For comparison of DAP and TP, patients with a pre-stroke $\mathrm{mRS}>1$ were excluded in order to minimize a bias on clinical outcome. $^{4} 5$ Subgroup comparisons were performed using Fisher's exact test for categorical data, Student's t-test for numerical and approximately normally distributed data, and the exact Mann-Whitney $U$ and Pearson $\chi^{2}$ test for non-parametric testing.

After excluding all patients with a pre-stroke $\mathrm{mRS}>0$ to further reduce bias on the outcome variables, patients were stratified in multiple ways according to their functional outcome (excellent $(m R S=0)$ vs all others; very good $(m R S=0-1)$ vs all others, and favorable $(\mathrm{mRS}=0-2)$ vs all other $\mathrm{mRS}$ ) and all baseline as well as procedural and process time parameters were tested for significant differences between these outcome groups. All variables showing a difference with a $\mathrm{p}$ value $<0.10$ were included into three separate multivariable logistic regression models, with excellent, very good, and favorable outcome as the dependent variable, respectively. $\mathrm{p}<0.05$ was used as a cut-off level for statistical significance.

Finally, logistic regressions were used to model the probability of the different possible functional outcomes (mRS after 90 days $(0 / 0-1 / 0-2))$ as functions of time from symptom onset to reperfusion, which were then represented graphically.

All statistical analyses were performed using SPSS V.22 (IBM, Armonk, New York, USA).

\section{RESULTS}

\section{Subjects and occlusion patterns}

Between February 2013 and February 2015, 100 patients treated with pREset for acute embolic stroke were included into the study. Eight patients had multiple intracranial occlusions resulting in 109 target vessels. Baseline clinical data are summarized in table 1.

\section{Recanalization success}

After the last pass with pREset, a successful recanalization (o-TICI 2b/3) was achieved in 92 of 109 treated vessels $(84.4 \%$ ) with a mean of 1.7 (SD 0.96 ; median 1 , range, 1-5) passes. 
Table 1 Baseline characteristics for all patients and separately for directly admitted and transferred patients

\begin{tabular}{|c|c|c|c|c|}
\hline \multirow[b]{2}{*}{ Baseline characteristics } & \multirow[b]{2}{*}{ All patients $(n=100)$} & \multicolumn{2}{|l|}{ Excluding pre-stroke $\mathrm{mRS}>1$} & \multirow[b]{2}{*}{ p Value } \\
\hline & & Transferred patients $(n=53)$ & Directly admitted patients $(n=38)$ & \\
\hline \multicolumn{5}{|l|}{ Age (years) } \\
\hline Mean (SD) & $68.3(13.8)^{*}$ & $69.2(11.5)$ & $66.1(16.4)$ & 0.292 \\
\hline Female sex, \% (n/n) & $55.0 \%(55 / 100)$ & $54.7 \%(29 / 53)$ & $53.3 \%(21 / 38)$ & 0.959 \\
\hline \multicolumn{5}{|l|}{ NIHSS score at admission } \\
\hline Median ( $\mathrm{n}$; range) & $15(99 ; 5-29) \dagger$ & $15(53 ; 6-29)$ & $14(37 ; 5-27)$ & 0.278 \\
\hline \multicolumn{5}{|l|}{ Medical history } \\
\hline Atrial fibrillation, $\%(n / n)$ & $57.1 \%(56 / 98)$ & $59.6 \%(31 / 52)$ & $52.6 \%(20 / 38)$ & 0.509 \\
\hline Systemic hypertension, $\%(n / n)$ & $67.3 \%(66 / 98)$ & $69.2 \%(36 / 52)$ & $62.2 \%(23 / 37)$ & 0.487 \\
\hline Diabetes, \% (n/n) & $17.2 \%(17 / 99)$ & $15.4 \%(8 / 52)$ & $13.2 \%(5 / 38)$ & 0.767 \\
\hline Former stroke, \% (n/n) & $16.3 \%(13 / 80)$ & $20.0 \%(9 / 45)$ & $10.0 \%(3 / 30)$ & 0.247 \\
\hline \multicolumn{5}{|l|}{ Pre-stroke mRS, \% (n/n) } \\
\hline 0 & $83.0 \%(83 / 100)$ & $92.5 \%(49 / 53)$ & $89.5 \%(34 / 38)$ & 0.715 \\
\hline $0-1$ & $91.0 \%(91 / 100)$ & $100.0 \%(53 / 53)$ & $100.0 \%(38 / 38)$ & NA \\
\hline $0-2$ & $96.0 \%(96 / 100)$ & NA & NA & NA \\
\hline$>2$ & $4.0 \%(4 / 100)$ & NA & NA & NA \\
\hline \multicolumn{5}{|l|}{ ASPECTS, \% (n/n) } \\
\hline $8-10$ & $95.8 \%(91 / 95)$ & $96.0 \%(48 / 50)$ & $94.4 \%(34 / 36)$ & 1.000 \\
\hline $5-7$ & $4.2 \%(4 / 95)$ & $4.0 \%(2 / 50)$ & $5.6 \%(2 / 36)$ & 1.000 \\
\hline $0-4$ & $0 \%(0 / 95)$ & $0.0 \%(0 / 50)$ & $0.0 \%(0 / 36)$ & NA \\
\hline Preprocedure IV lysis, \% (n/n) & $63.0 \%(63 / 100)$ & $66.0 \%(35 / 53)$ & $60.5 \%(23 / 38)$ & 0.590 \\
\hline General anesthesia, \% ( $\mathrm{n} / \mathrm{n})$ & $88.0 \%(88 / 100)$ & $90.6 \%(48 / 53)$ & $81.6 \%(31 / 38)$ & 0.211 \\
\hline Higashida collateral score median ( $\mathrm{n}$; range) & $2(92 ; 0-4)$ & $2(49 ; 0-4)$ & $1(35 ; 0-3)$ & 0.339 \\
\hline \multicolumn{5}{|l|}{ Occlusion site, \% (n/n vessels) } \\
\hline MCA & $74.3 \%(81 / 109)$ & $73.7 \%(42 / 57)$ & $71.7 \%(33 / 46)$ & 0.825 \\
\hline ICA & $13.8 \%(15 / 109)$ & $15.8 \%(9 / 57)$ & $13.0 \%(6 / 46)$ & 0.694 \\
\hline BA & $7.3 \%(8 / 109)$ & $5.3 \%(3 / 57)$ & $10.9 \%(5 / 46)$ & 0.462 \\
\hline PCA & $3.7 \%(4 / 109)$ & $5.3 \%(3 / 57)$ & $2.2 \%(1 / 46)$ & 0.626 \\
\hline ACA & $0.9 \%(1 / 109)$ & $0.0 \%(0 / 57)$ & $2.2 \%(1 / 46)$ & 0.447 \\
\hline Multiple occlusions, \% (n/n vessels) & $8.3 \%(9 / 109)$ & $8.8 \%(5 / 57)$ & $8.7 \%(4 / 46)$ & 0.715 \\
\hline Stenting cervical ICA, \% (n/n) & $14 \%(14 / 100)$ & $17.0 \%(9 / 53)$ & $13.2 \%(5 / 38)$ & 0.618 \\
\hline
\end{tabular}

According to the performing interventionalist's individual decision, other devices were used after pREset, treating 6.4\% of the vessel occlusions ( $\mathrm{n}=5 \mathrm{MCA}, \mathrm{n}=2 \mathrm{ICA})$. Supplementary devices were Solitaire FR $(n=4)$, Trevo $(n=1)$, Eric (MicroVention, Tustin, California, USA) $(n=1)$, or angioplasty $(n=1)$. In one of these cases recanalization could be improved to o-TICI $2 b / 3$. Thus, the overall rate of successfully recanalized vessels was 93 of $109(85.3 \%)$.

\section{Safety}

Ten (10\%) potentially device-related complications occurred $(n=2$ extravasations, $n=3$ vasospasms, $n=2$ emboli to a new territory, $\mathrm{n}=3$ emboli to the same territory) but none was associated with a clinical deterioration. Post-treatment imaging revealed seven focal subarachnoid hemorrhages around the target vessel (7\%), four (4\%) PH I, and three (3\%) PH II. Two patients developed a remote subdural hematoma (2\%), probably owing to trauma in combination with IVT. Two (2\%) hemorrhages were classified as symptomatic.

\section{Clinical outcome}

At 24-72 hours after recanalization, patients showed a median NIHSS score of $5(n=99$; range, $0-42)$. At this time, a great clinical improvement of at least 10 points, according to the NIHSS, was seen in 36 of 98 patients (36.7\%). At discharge the median NIHSS score was $2(n=94$; range, $0-27)$, and 23 of 94 patients $(24.5 \%)$ showed complete remission of neurological symptoms (NIHSS 0).

Follow-up at 90 days was available for 96 of 100 patients. Favorable clinical outcome was found in $62.5 \%(60 / 96)$ of the patients, $54.2 \%$ (52/96) showed a very good outcome, and $24.0 \%(23 / 96)$ an excellent outcome.

Death rate at 90 days was $7.3 \%$ (7/96). Of these, four patients died during the hospital stay, three were caused by malignant cerebral infarction and one was caused by the development of contralateral MCA occlusion. Of the remaining three patients, one died owing to the severity of the stroke, one presumably developed a recurrent stroke, and in one patient the cause of death was unknown.

\section{Comparison of DAP and TP}

After exclusion of nine patients with pre-stroke $\mathrm{mRS}>1,38$ DAP and 53 TP remained for further analysis. The two groups did not differ in baseline clinical data (table 1). In TP, the time from stroke onset to admission in the endovascular stroke center was significantly increased, whereas the time from 
Ischemic stroke

Table 2 Process time parameters for all, transferred and directly admitted patients

\begin{tabular}{|c|c|c|c|c|}
\hline \multirow[b]{2}{*}{$\begin{array}{l}\text { Process time parameters } \\
\text { (min) }\end{array}$} & \multirow[b]{2}{*}{$\begin{array}{l}\text { All patients } \\
(n=100)\end{array}$} & \multicolumn{2}{|c|}{ Excluding pre-stroke $\mathrm{mRS}>1$} & \multirow[b]{2}{*}{ p Value } \\
\hline & & $\begin{array}{l}\text { Transferred patients } \\
(n=53)\end{array}$ & $\begin{array}{l}\text { Directly admitted patients } \\
(n=38)\end{array}$ & \\
\hline \multicolumn{5}{|l|}{ Stroke onset to admission } \\
\hline Median (n; range) & $145(92 ; 9-396)$ & $188(51 ; 73-369)$ & $61(34 ; 9-220)$ & $<0.001$ \\
\hline \multicolumn{5}{|l|}{ Admission to groin puncture } \\
\hline Median (n; range) & $58.5(92 ; 5-187)$ & $45(51 ; 5-150)$ & $76(34 ; 15-187)$ & $<0.001$ \\
\hline \multicolumn{5}{|l|}{ Groin puncture to reperfusion } \\
\hline Median (n; range) & $40(100 ; 6-159)$ & $49(53 ; 6-159)$ & $36(38 ; 8-116)$ & 0.943 \\
\hline \multicolumn{5}{|l|}{ Stroke onset to reperfusion } \\
\hline Median (n; range) & 247 (99; 112-469) & $289(53 ; 172-469)$ & $180(38 ; 112-386)$ & $<0.001$ \\
\hline
\end{tabular}

Table 3 Technical and clinical outcome for all, transferred and directly admitted patients

\begin{tabular}{|c|c|c|c|c|}
\hline \multirow[b]{2}{*}{ Technical/clinical outcome } & \multirow[b]{2}{*}{$\begin{array}{l}\text { All patients } \\
(n=100)\end{array}$} & \multicolumn{2}{|c|}{ Excluding pre-stroke $\mathrm{mRS}>1$} & \multirow[b]{2}{*}{$p$ Value } \\
\hline & & $\begin{array}{l}\text { Transferred patients } \\
(n=53)\end{array}$ & $\begin{array}{l}\text { Directly admitted patients } \\
(n=38)\end{array}$ & \\
\hline \multicolumn{5}{|l|}{ Final $0-\mathrm{TICl} 2 \mathrm{~b}-3$ only pREset } \\
\hline$\%$ (n/n vessels) & $84.4 \%(92 / 109)$ & $84.2 \%(48 / 57)$ & $82.6 \%(38 / 46)$ & 0.828 \\
\hline \multicolumn{5}{|l|}{ Final o-TICI 2b-3 overall } \\
\hline$\%$ (n/n vessels) & $85.3 \%(93 / 109)$ & $86.0 \%(49 / 57)$ & $82.6 \%(38 / 46)$ & 0.640 \\
\hline \multicolumn{5}{|c|}{ Passages until final o-TICl overall } \\
\hline Mean ( $\mathrm{n}$ vessels; SD) & $1.91(109 ; 1.31)$ & $1.95(57 ; 1.38)$ & $1.91(46 ; 1.30)$ & 0.898 \\
\hline \multicolumn{5}{|l|}{ Intraprocedural complications } \\
\hline$\%(n / n)$ & $10.0 \%(10 / 100)$ & $9.4 \%(5 / 53)$ & $13.2 \%(5 / 38)$ & 0.575 \\
\hline \multicolumn{5}{|l|}{ Emboli to new or same territory } \\
\hline$\%(n / n)$ & $5.0 \%(5 / 100)$ & $1.9 \%(1 / 53)$ & $10.5 \%(4 / 38)$ & 0.157 \\
\hline \multicolumn{5}{|l|}{ Hemorrhage post } \\
\hline Any hemorrhage, $\%(n / n)$ & $14.0 \%(14 / 100)$ & $13.2 \%(7 / 53)$ & $18.4 \%(7 / 38)$ & 0.497 \\
\hline Parenchymal, \% (n/n) & $6.0 \%(6 / 100)$ & $7.5 \%(4 / 53)$ & $5.3 \%(2 / 38)$ & 1.000 \\
\hline Subarachnoid, \% (n/n) & $7.0 \%(7 / 100)$ & $3.8 \%(2 / 53)$ & $13.2 \%(5 / 38)$ & 0.124 \\
\hline Subdural, \% (n/n) & $2.0 \%(2 / 100)$ & $3.8 \%(2 / 53)$ & $0.0 \%(0 / 38)$ & 0.508 \\
\hline Symptomatic, \% (n/n) & $2.0 \%(2 / 100)$ & $1.9 \%(1 / 53)$ & $2.6 \%(1 / 38)$ & 1.000 \\
\hline \multicolumn{5}{|l|}{ NIHSS at $24-72$ hours } \\
\hline Median (n; range) & $5(99 ; 0-42)$ & $6(52 ; 0-42)$ & $3(38 ; 0-22)$ & 0.005 \\
\hline \multicolumn{5}{|l|}{ NIHSS at discharge $=0$} \\
\hline$\%(n / n)$ & $24.5 \%(23 / 94)$ & $16.7 \%(8 / 48)$ & $36.8 \%(14 / 38)$ & 0.033 \\
\hline \multicolumn{5}{|l|}{ mRS after 90 days; $\%(n / n)$} \\
\hline 0 & $24.0 \%(23 / 96)$ & $16.0 \%(8 / 50)$ & $40.5 \%(15 / 37)$ & 0.010 \\
\hline $0-1$ & $54.2 \%(52 / 96)$ & $48.0 \%(24 / 50)$ & $73.0 \%(27 / 37)$ & 0.019 \\
\hline $0-2$ & $62.5 \%(60 / 96)$ & $58.0 \%(29 / 50)$ & $78.4 \%(29 / 37)$ & 0.046 \\
\hline $3-5$ & $30.2 \%(29 / 96)$ & $36.0 \%(18 / 50)$ & $18.9 \%(7 / 37)$ & 0.082 \\
\hline 6 & $7.3 \%(7 / 96)$ & $6.0 \%(3 / 50)$ & $2.7 \%(1 / 37)$ & 0.633 \\
\hline
\end{tabular}

admission to groin puncture was shorter than for DAP. The time from groin puncture to reperfusion did not differ. Overall, the vessel occlusion time (stroke onset to reperfusion) was significantly longer in TP (table 2). Regarding clinical results the NIHSS at 24-72 hours and at discharge was significantly higher in TP and the rate of favorable $(\mathrm{mRS}=0-2)$, very good $(\mathrm{mRS}=0-1)$, and excellent $(\mathrm{mRS}=0)$ outcome was significantly lower, yet the death rate remained equal (table 3). DAP were more than twice as likely to achieve a favorable outcome than $\mathrm{TP}(\mathrm{OR}=2.63$, CI 1.002 to $6.879, \mathrm{p}=0.046)$.

Assessing the process time parameters, no significant differences were found between the four study centers (each $\mathrm{p}>0.07)$. Analogously, no significant differences were found in the rates of excellent $(p=0.354)$, very good $(p=0.564)$, or favorable clinical outcome $(p=0.282)$ at 90 days, suggesting a negligible center bias. However, the proportion of transferred 


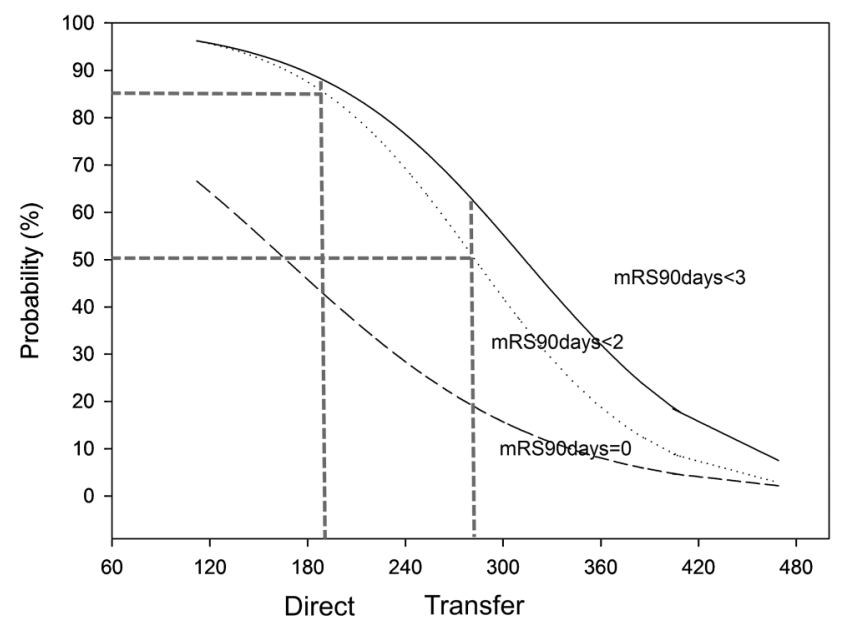

Stroke onset to reperfusion ( $\mathrm{min})$

-....... Probability of favorable clinical outcome (mRS at 90 days $<3$ )
Prity of very good clinical outcome (mRS at 90 days $<2)$

--- Probability of excellent clinical outcome $(\mathrm{mRS}$ at 90 days $=0)$

Figure 2 Probability curves for excellent (modified Rankin Scale $(m R S)=0)$, very good $(m R S<2)$ and favorable $(m R S<3)$ outcome at 90 days depending on the time between stroke onset and reperfusion. The drop lines represent the median time from stroke onset to reperfusion of directly admitted (185.50 min) versus transferred patients (280.33 min) indicating a probability for a very good outcome of $86.4 \%$ vs $51.2 \%$, respectively. Min, minutes.

and primarily admitted patients differed $(80.0 \%$ vs $57.1 \%$, $48.5 \%$, and $42.1 \% ; \mathrm{p}=0.043$ ).

The following variables showed a difference $(p<0.10)$ in at least one group comparison after stratifying patients according to their clinical outcome and were therefore included in the multivariable logistic regression models: baseline (mRS at admission, NIHSS at admission, Alberta Stroke Program Early CT Score (ASPECTS), occlusion sites, collateral status), medical history (systemic hypertension, diabetes mellitus), procedural variables (device passages, additional devices, embolization), all time parameters, and finally, transfer status of the patients.

Time from symptom onset to reperfusion $(\mathrm{OR}=0.977$, CI 0.965 to $0.990, \mathrm{p}<0.001)$, NIHSS at admission $(\mathrm{OR}=0.836, \mathrm{CI}$ 0.737 to $0.949, \mathrm{p}=0.005)$, and diabetes mellitus $(\mathrm{OR}=0.086$, CI 0.013 to $0.556, \mathrm{p}=0.010$ ) were shown to be independent predictors for a favorable clinical outcome, yet transfer status showed no significant association with a favorable outcome $(\mathrm{OR}=0.565$, CI 0.133 to $2.393, \mathrm{p}=0.438)$.

Based on the logistic regression models, the likelihoods of excellent, very good, and favorable outcomes at 90 days $(\mathrm{mRS}=0,0-1,0-2)$ all decreased as a function of time to reperfusion (figure 2). Furthermore, the likelihood of an excellent outcome at 90 days $(\mathrm{mRS}=0)$ dropped substantially earlier than the likelihoods of good or favorable outcomes, suggesting an indicative left shift for an excellent outcome on the timeline.

\section{DISCUSSION}

In this study, we analyzed technical and clinical outcome as well as adverse events in patients treated with the pREset thrombectomy device for acute ischemic stroke caused by occlusion of a proximal cerebral vessel either in the anterior or posterior circulation.

The rate of successful recanalization was $84.4 \%$ and therefore high compared with rates reported by previously published single-center studies using the same device. ${ }^{12}{ }^{13}$ Intraprocedural potentially device-related complications were seen in $10 \%$ but none were clinically relevant, which is in agreement with the low complication rates of the SWIFT PRIME trial and the retrospective analyses of the pREset thrombectomy device. ${ }^{5} \quad 12 \quad 13$ Similarly, the overall rates of all and symptomatic hemorrhages were in line with data on other stent retriever studies. ${ }^{3} 42324$

The 90 -day mortality of $7.3 \%$, as found in this study, is close to the lower end of the mortality rates reported by most recent RCTs, which range between $9 \%$ and $21 \%$, and thus is comparable to these. ${ }^{1-5}$

Recent RCTs reported rates of a favorable clinical outcome, represented by a 90-day mRS of $0-2$, ranging between $33 \%$ (MR CLEAN) and 71\% (EXTEND-IA). Functional outcome is critically determined by successful reperfusion, which was lowest in MR CLEAN (59\% m-TICI 2b/3) and highest in EXTEND-IA $(86 \%$ modified Thrombolysis in Cerebral Infarction score (m-TICI) 2b/3). ${ }^{12}$ The superior effect of stent retrievers on recanalization results and clinical outcome has been proved previously in two device comparison studies (TREVO 2, SWIFT). ${ }^{10} 11$

Another important factor influencing outcome is patient selection. Inclusion and exclusion criteria of our study were similar to those of MR CLEAN. ${ }^{1}$ Although the purpose of this study was to assess the performance of a specific device, MR CLEAN allowed for any endovascular approach. Also, in contrast, we included patients with occlusions in the posterior circulation; nevertheless, rates of successful recanalization were substantially higher. Hence, comparatively high rates of favorable functional outcome might be due to high recanalization rates achieved with the pREset thrombectomy device. However, in contrast to the MR CLEAN trial the interventionalists of our study had to perform at least 25 procedures with the study device before enrolling patients, whereas only five procedures were required for the MR CLEAN trial. It should be noted that these comparatively higher requirements for the interventionalists participating in our study might have caused a training bias, leading to a better technical and clinical outcome in comparison with the outcome of other trials, such as the MR CLEAN trial. Additionally, the median NIHSS score at admission was slightly lower (15 vs 17), which might also have contributed to the better clinical outcome in our study compared with the MR CLEAN trial, ${ }^{1}$ which might affect the generalizability of our results. Moreover, 95.8\% of the patients selected for this study had ASPECT scores of $\geq 8$ and $91 \%$ of these patients had a prestroke mRS of 0 or 1 , which might have caused an additional selection bias.

An additional objective of this study was the subgroup analysis comparing referred patients with those who were directly admitted to one of the endovascular stroke centers. In referred patients, the median time from symptom onset to arrival at a stroke center was significantly longer. This substantial delay was attributable to additional transportation time and medical measures taken at the peripheral hospitals as well as IVT in eligible patients. MT was started significantly more quickly in TP after arrival at a stroke center, because imaging was already available. However, this could not compensate for the loss of time caused by the secondary transport and thus the time from symptom onset to recanalization was significantly longer in TP.

In patients directly admitted to one of the endovascular stroke centers, a favorable clinical outcome was more than twice as likely as in referred patients. In the multivariable logistic regression analysis, only the time from symptom onset to 
reperfusion, diabetes mellitus, and the NIHSS at admission were identified as independent predictors for excellent, very good, and favorable outcome. Since the NIHSS and presence of diabetes mellitus did not differ between the subgroups, the longer duration of vessel occlusion in referred patients can be regarded as the main reason for the significantly lower rate of a favorable outcome. This association of time parameters and functional outcome is well known for IVT and it also applies to endovascular stroke treatment: a post hoc analysis of IMS-III, MR CLEAN, and SWIFT PRIME showed a significant association between time to reperfusion and clinical outcome. ${ }^{16} 1925$ In a retrospective single-center study, Sun et $a l^{18}$ previously reported a similar correlation between long occlusion times and less favorable outcome in referred patients. This effect seems to be particularly distinct in patients with poor collaterals. ${ }^{14}$ Also, in the recent SWIFT study, the time between symptom onset and admission of $<3$ hours was associated with favorable functional outcome at 90 days. $^{17}$

Our study clearly underlines the association of a shorter time between symptom onset and recanalization and a better functional outcome. This effect becomes more pronounced for stricter outcome measures, such as very good and excellent functional results (figure 2).

Our results have implications for future healthcare organization of endovascular treatment of patients with acute stroke. Endovascular stroke therapy requires dedicated technical equipment suitable for cerebral angiography and highly trained interventionalists to perform the procedure safely and effectively. Thus, a nationwide coverage comparable to IVT cannot be achieved. A direct transfer of all patients with stroke to centers with endovascular treatment expertise might serve as a solution at first glance. On the other hand, only about $10 \%$ of stroke victims are potential candidates for thrombectomy and unselected referral will unnecessarily bind capacities of highly specialized centers. Pre-hospital triage of patients with stroke based on clinical scales might solve this problem, but this still needs further validation. ${ }^{26-28}$ Yet, very fast brain and vessel imaging in the primary admitting hospital is necessary, allowing for quick identification of candidates for endovascular therapy and instantaneous transfer. Ambulance services need to set these patients at top priority and, possibly, new structures for transportation need to be established, especially in rural areas (eg, increasing capacities for day and night helicopter transportation).

\section{CONCLUSIONS}

pREset proved to be safe and effective for the treatment of acute embolic intracranial vessel occlusion. Increased occlusion time impaired clinical outcome in TP. Reorganization of healthcare is urgently required to minimize this obvious disadvantage.

\footnotetext{
Acknowledgements Professor Dr Stephan Felber, MD (Gemeinschaftsklinikum Mittelrhein, Institut für Diagnostische und Interventionelle Radiologie und Neuroradiologie, Koblenz, Germany) provided all core-laboratory services for this study. Tine Willems, PhD (T!Write, Kalken, Belgium) performed all statistical analysis for this manuscript.
}

Contributors SP and WK: study design, analysis of results, critical data review, interpretation of data. BJS, ASG, AF, and WK: interpretation of data, critical evaluation and revision of the manuscript. SP, WR, TN, and WK: data collection, interpretation of the data. SP: primary manuscript writing, tables and figures. All authors contributed intellectually.

Funding This study received funding from phenox $\mathrm{GmbH}$, Bochum, Germany. Competing interests SP and WK are consultants for phenox GmbH, Bochum, Germany.

\section{Patient consent Obtained.}

Ethics approval Ethics committees of Universitätsklinikum des Saarlandes; Klinikum rechts der Isar, Technische Universität München; Universitätsklinikum Münster; Klinikum Stuttgart.

Provenance and peer review Not commissioned; externally peer reviewed.

Open Access This is an Open Access article distributed in accordance with the Creative Commons Attribution Non Commercial (CC BY-NC 4.0) license, which permits others to distribute, remix, adapt, build upon this work non-commercially, and license their derivative works on different terms, provided the original work is properly cited and the use is non-commercial. See: http://creativecommons.org/ licenses/by-nc/4.0/

\section{REFERENCES}

1 Berkhemer OA, Fransen PS, Beumer D, et al. A randomized trial of intraarterial treatment for acute ischemic stroke. N Engl J Med 2015;372:11-20.

2 Campbell BC, Mitchell PJ, Kleinig TJ, et al. Endovascular therapy for ischemic stroke with perfusion-imaging selection. N Engl J Med 2015;372:1009-18.

3 Goyal M, Demchuk AM, Menon BK, et al. Randomized assessment of rapid endovascular treatment of ischemic stroke. N Engl J Med 2015; 372:1019-30.

4 Jovin TG, Chamorro A, Cobo E, et al. Thrombectomy within 8 hours after symptom onset in ischemic stroke. N Engl J Med 2015;372:2296-306.

5 Saver JL, Goyal M, Bonafe A, et al. Stent-retriever thrombectomy after intravenous t-PA vs. t-PA alone in stroke. N Engl J Med 2015:372:2285-95.

6 Pérez MA, Miloslavski E, Fischer $S$, et al. Intracranial thrombectomy using the Solitaire stent: a historical vignette. J Neurointerv Surg 2012;4:e32.

7 Broderick JP, Palesch YY, Demchuk AM, et al. Endovascular therapy after intravenous t-PA versus t-PA alone for stroke. $N$ Engl I Med 2013;368:893-903.

8 Kidwell CS, Jahan R, Gornbein J, et al. A trial of imaging selection and endovascular treatment for ischemic stroke. N Engl J Med 2013; 368:914-23

9 Ciccone A, Valvassori L, Nichelatti $M$, et al. Endovascular treatment for acute ischemic stroke. N Engl J Med 2013;368:904-13.

10 Nogueira RG, Lutsep HL, Gupta R, et al. Trevo versus Merci retrievers for thrombectomy revascularisation of large vessel occlusions in acute ischaemic stroke (TREVO 2): a randomised trial. Lancet 2012;380:1231-40.

11 Saver JL, Jahan R, Levy El, et al. Solitaire flow restoration device versus the Merci Retriever in patients with acute ischaemic stroke (SWIFT): a randomised, parallel-group, non-inferiority trial. Lancet 2012;380:1241-9.

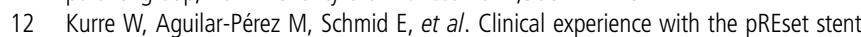
retriever for the treatment of acute ischemic stroke--a review of 271 consecutive cases. Neuroradiology 2014;56:397-403.

13 Schwaiger BJ, Kober F, Gersing AS, et al. The pREset stent retriever for endovascular treatment of stroke caused by MCA occlusion: safety and clinical outcome. Clin Neuroradiol 2016;26:47-55.

14 Hwang YH, Kang DH, Kim YW, et al. Impact of time-to-reperfusion on outcome in patients with poor collaterals. AJNR Am J Neuroradiol 2015;36:495-500.

15 Khatri P, Abruzzo T, Yeatts SD, et al. Good clinical outcome after ischemic stroke with successful revascularization is time-dependent. Neurology 2009;73:1066-72.

16 Khatri P, Yeatts SD, Mazighi M, et al. Time to angiographic reperfusion and clinical outcome after acute ischaemic stroke: an analysis of data from the Interventional Management of Stroke (IMS III) phase 3 trial. Lancet Neurol 2014;13:567-74.

17 Liebeskind DS, Jahan R, Nogueira RG, et al. Early arrival at the emergency department is associated with better collaterals, smaller established infarcts and better clinical outcomes with endovascular stroke therapy: SWIFT study. J Neurointerv Surg 2016;8:553-8.

18 Sun $\mathrm{CH}$, Nogueira RG, Glenn BA, et al. "Picture to puncture": a novel time metric to enhance outcomes in patients transferred for endovascular reperfusion in acute ischemic stroke. Circulation 2013;127:1139-48.

19 Fransen PS, Berkhemer OA, Lingsma HF, et al. Time to reperfusion and treatment effect for acute ischemic stroke: a randomized clinical trial. JAMA Neurol 2016;73:190-6.

20 Higashida RT, Furlan AJ, Roberts $\mathrm{H}$, et al. Trial design and reporting standards for intra-arterial cerebral thrombolysis for acute ischemic stroke. Stroke 2003;34: e109-37.

21 Berger $C$, Fiorelli M, Steiner $T$, et al. Hemorrhagic transformation of ischemic brain tissue: asymptomatic or symptomatic? Stroke 2001;32:1330-5

22 van Swieten JC, Koudstaal PJ, Visser MC, et al. Interobserver agreement for the assessment of handicap in stroke patients. Stroke 1988;19:604-7.

23 Pereira VM, Gralla J, Davalos A, et al. Prospective, multicenter, single-arm study of mechanical thrombectomy using Solitaire flow restoration in acute ischemic stroke. Stroke 2013;44:2802-7.

24 Jansen O, Macho JM, Killer-Oberpfalzer M, et al. Neurothrombectomy for the treatment of acute ischemic stroke: results from the TREVO study. Cerebrovasc Dis 2013;36:218-25 
25 Goyal M, Jadhav AP, Bonafe A, et al. Analysis of workflow and time to treatment and the effects on outcome in endovascular treatment of acute ischemic stroke: results from the SWIFT PRIME randomized controlled trial. Radiology 2016;279:888-97.

26 Hastrup S, Damgaard D, Johnsen SP, et al. Prehospital acute stroke severity scale to predict large artery occlusion: design and comparison with other scales. Stroke 2016:47:1772-6.
27 Heldner MR, Hsieh K, Broeg-Morvay A, et al. Clinical prediction of large vessel occlusion in anterior circulation stroke: mission impossible? J Neurol 2016;263:1633-40.

28 Lima FO, Silva GS, Furie KL, et al. Field assessment stroke triage for emergency destination: a simple and accurate prehospital scale to detect large vessel occlusion strokes. Stroke 2016;47:1997-2002. 